\title{
A CONSTRUCÃO DO CONHECIMENTO CIENTÍFICO ESCOLAR: HIPÓTESES DE TRANSIĈ̣̃O IDENTIFICADAS A PARTIR DAS IDEIAS DOS(AS) ALUNOS(AS)
}

\author{
FERNANDA DA ROCHA CARVALHO ${ }^{*}$ \\ ORCID: https://orcid.org/00000-0001-8481-5626 \\ GISELLE WATANABE ${ }^{\prime * *}$ \\ ORCID: https://orcid.org/0000-0002-3738-7160
}

RESUMO: A escola vem incorporando discussão cerca das questões socioambientais seja devido às orientações curriculares ou abordagens midiáticas. A forma como elas vêm sendo tratadas divergem significativamente, seja do ponto de vista das estratégias utilizadas ou da própria concepção de ciência. No último caso, nota-se certa preocupação em indicar a perspectiva da complexidade como elemento orientador dessa reflexão. Considerando esses pressupostos e preocupados como a aprendizagem que vem se estabelecendo diante desse cenário, esse artigo investiga a "evolução" das ideias dos(as) alunos(as) do Ensino Médio ao participarem de uma proposta de aulas sobre o Aquecimento Global. Dos resultados, tendo como base as hipóteses de transição, foi possível identificar os percursos das ideias dos(as) estudantes ao se depararem com situações cada vez mais complexas. Nota-se que o sistema de ideias, que incluem posicionamentos sobre o ambiente, são muito dinâmicos, de forma que atingem diferentes níveis de aprendizagem em distintos momentos. Assim, nesse processo há espaços para que o(a) estudante transforme seu pensamento reducionista para um mais crítico, complexo e reflexivo, a ponto de desenvolver a responsabilidade política, cultural, econômica, social etc.

Palavras-chave:Ensino de física. Meio ambiente. Complexidade. Conhecimento científico escolar. Hipóteses de transição.

\footnotetext{
'Universidade Federal do ABC, Programa Ensino, História e Filosofia das Ciências e Matemática, ABC Paulista, SP, Brasil.

"Universidade Federal do ABC, Centro de Ciências Naturais e Humanas, ABC Paulista, SP, Brasil.

"Programa Ensino, História e Filosofia das Ciências e Matemática / UFABC.

E-mail:<carvalho.fernanda@ufabc.edu.br > .

" Centro de Ciências Naturais e Humanas / Universidade Federal do ABC.

E-mail:< giselle.watanabe@ufabc.edu.br $>$.
} 


\section{THE CONSTRUCTION OF SCHOLARLY SCIENTIFIC KNOWLEDGE: TRANSITIONAL LEVELS IDENTIFIED AS OF THE STUDENTS'S IDEAS}

ABSTRACT: The school has been incorporating discussion about socioenvironmental issues due to curricular guidelines or media pressures. The way they are treated differ significantly, either from the point of view of the strategies used or from the very conception of science. In the latter case, there is a certain concern to indicate the perspective of complexity as guiding element of this reflection. Considering these presuppositions and worried as learning has been established in this context, this article investigates the "evolution" of the ideas of the students of the High School when participating in a proposal of classes on Global Warming. From the results, based on the transition hypotheses, it was possible to identify the paths of students' ideas when faced with increasingly complex situations. It is noted that the system of ideas, which include positions on the environment, are very dynamic, so that they reach different levels of learning at different times. Thus, in this process there are spaces for the student to transform his reductionist thinking into a more critical, complex and reflexive one, to the point of developing political, cultural, economic, social, and other responsibilities.

Keywords: Physics teaching. Environment. Complexity. Scholarly scientific knowledge. Transitions levels.

\section{INTRODUĈ̣̃O}

As questões de natureza socioambiental estão cada vez mais presentes no cotidiano das pessoas, seja devido às abordagens realizadas pelos meios de comunicação ou às situações de risco que vivenciam em seu entorno. Em muitos casos os discursos presentes nesses meios e na própria escola estão embasados por uma reflexão mais reducionista, que privilegia apenas um ponto de vista e desconsideram as relações complexas que se estabelecem com os conhecimentos sociais, econômicos, culturais, políticos etc.

No contexto do Ensino e da Educação essas questões se desenvolvem nas discussões ou publicações realizadas em encontros de pesquisadores ou nas reflexões presentes nos documentos oficiais que orientam a educação básica, como os Parâmetros Curriculares Nacionais para o Ensino Médio (PCNEM) (BRASIL, 2002), as Orientações curriculares para o Ensino Médio (BRASIL, 2006) e as Diretrizes Curriculares Nacionais para o Ensino Médio (DCNEM) 
(BRASIL, 1998). Tais documentos compreendem a importância de um ensino pautado nas práticas sociais e culturais e numa formação ética capaz de lidar com a sociedade contemporânea. O PCNEM, por exemplo, considera a potencialidade dos temas socioambientais ao integrar os conceitos específicos de outras áreas do conhecimento como a Física, Biologia, Química, Geografia, entre outros, buscando, por meio das interelações, superar a visão fragmentada do conhecimento ambiental. No que se referem às DCNEM, os estudos do meio ganham destaque visto que podem promover a responsabilidade e participação do indivíduo no meio em que vive. De forma geral, podemos entender que esses documentos apontam para uma Educação Ambiental (EA) em que as práticas escolares não se voltam às ações pontuais (a exemplo das atividades de reciclagem ou plantio de árvores), mas à articulação de diferentes pontos de vista.

De modo geral, as reflexões e ações voltadas aos problemas socioambientais apresentam um caráter tímido e muitas vezes desvinculado dos conceitos curriculares o que, por sua vez, pode gerar uma discussão mais superficial acerca do assunto. Nessa linha, Loureiro (2008) e Guimarães (2008) defendem que a escola enquanto um instrumento funcional à sociedade deve superar os ensinos conduzidos por raras reflexões críticas e pouco questionadores. Para eles, nada adianta a inserção da EA no currículo escolar sem considerar os processos sociais, as interações de poder, as regras institucionais, as condições de trabalho docente e a comunidade na qual o(a) aluno(a) está imerso(a). Numa perspectiva semelhante, García (1998) refere-se à EA enquanto uma porta de entrada para a reorganização do saber e uma outra forma de atuar e tratar os problemas socioambientais. Para ele, há de se romper com uma visão de mundo estática e simplificadora, em contraposição a uma nova visão dinâmica e articulada, tal como a da complexidade. O autor destaca que a EA possibilita a desconstrução da visão ambientalista predominante, na qual o homem precisa se afastar da natureza para conservá-la.

Em convergência com essas ideias e partindo do pressuposto que o desenvolvimento de uma EA mais crítica, complexa e reflexiva pode promover uma prática educativa que forme indivíduos capazes de responder as demandas de suas realidades, nesse artigo propõese investigar o processo de construção das ideias dos(as) alunos(as) (percursos de aprendizagem) ao participarem de uma proposta de aulas complexificada sobre o tema Aquecimento Global (AG). Para tanto, consideram-se as hipótese de transição (García, 2004) como elementos que contribuem na identificação do processo de aprendizagem no contexto da complexidade. 
Como forma de organização, em um primeiro momento discute-se a fundamentação teórica pautada em uma EA Crítica, Complexa e Reflexiva (aspectos já identificados por WatanabeCaramello e Kawamura, 2014). Em seguida, discute-se o conceito do conhecimento científico escolar e as hipóteses de transição (GARCÍA, 1998). Esta última tomada como um instrumento que ajuda na identificação e compreensão da forma de construção das ideias dos(as) estudantes frente a um conhecimento científico escolar. No momento seguinte, apresenta-se a proposta de aulas complexificada sobre AG e o contexto escolar analisado. Por fim, analisam-se as construções das ideais dos(as) alunos(as) ao longo das aulas.

\section{FUNDAMENTAĈ̣̃O TEÓRICA: EA CRÍTICA, COMPLEXA E REFLEXIVA E AS HIPÓTESES DE TRANSIC̣̃̃O}

A opção por se tratar da criticidade, complexidade e reflexividade na EA se dá visto as distintas contribuições que cada uma dessas abordagens traz para uma formação escolar mais completa. De antemão, destaca-se que a EA na perspectiva da Criticidade (FREIRE, 2005; GUIMARÃES E LOUREIRO, 2008) procura integrar e desenvolver os problemas socioambientais; a EA na perspectiva da Complexidade volta-se à uma formação mais ampla, pautada na complexificação do conhecimento escolar e na ideia de descomplexificação do sistema. (GARCÍA, 1998; GARCÍA, 2017); e a EA na perspectiva Reflexiva trata das relações e interferências sociais e históricas que existem em uma sociedade de risco (BECK, 2010), considerando como aspecto fundamental a reflexividade.

Já, as hipóteses de transição (GARCÍA, 1998; RODRÍGUEZMARÍN; FERNÁNDEZ-ARROYO E GARCÍA, 2014; MARTÍN, R. P; RIVERO A. G; SOLÍS E. R , 2017) refere-se a uma abordagem que pode orientar o trabalho em sala de aula, visto que traz indicações acerca de como os(as) estudantes mudam seus sistemas de ideias; as alterações possíveis durante o processo e as certezas e incertezas que vão acontecer ao longo das aulas.

\section{PRESSUPOSTOS PARA UMA EA MAIS CRÍTICA, COMPLEXA E REFLEXIVA}

Um ensino capaz de formar cidadãos e cidadãs com habilidades para lidar com situações presentes em seus cotidianos ainda é uma das grandes dificuldades enfrentadas pela educação do século XXI. O processo de ensino-aprendizagem, do nosso ponto de vista, deveria promover uma formação capaz de incorporar discussões vinculadas 
às questões socioambientais, próximas à realidade e embasadas pelo conhecimento social, científico, cultural, econômico etc. Essa formação implicaria também promover reflexões que culminem em posicionamentos que podem ser revistos e alterados quando novos argumentos mobilizarem os(as) alunos(as).

Nesse sentido, pautando-se na ideia da criticidade, o ensino deve promover aulas que mobilizem um pensamento transformador, tomando a Educação Ambiental Crítica e as considerações freireanas (Guimarães, 2008; Loureiro, 2008; Freire, 2005) como aspectos orientadores do processo. A proximidade dos problemas reais figura como elementos chaves para uma proposta que busca um posicionamento mais crítico dos indivíduos. Considera-se que o ser humano é parte integrante da natureza, assim, o ensino deveria ser pautado na relação entre a ação humana e o meio ambiente para que, com isso, ocorra uma articulação entre os aspectos sociais no contexto das questões socioambientais. Deste modo, na perspectiva da criticidade o propósito volta-se à difusão do conhecimento, à problematização, à responsabilidade e à consciência socioambiental.

Segundo Guimarães (2008), a EA desenvolvida nas escolas remete a uma produção de conhecimento conteudista, racionalista e comportamentalista. Isso reforça aspectos ecológicos e ambientalistas, promovendo uma visão simplificadora de compreender os fenômenos e os processos da natureza. Embora, o autor ressalte que os trabalhos dessa natureza são importantes e devem ser reconhecidos, destaca que suas estratégias não podem estar baseadas apenas em resolução de problemas. Loureiro (2008) alega que a produção do conhecimento deve ser constituída por movimentos e interações entre o indivíduo e a sociedade.

Com relação à complexidade, García (1998; 2004; 2017) e Morin (2007) apontam para a necessidade de construir uma visão de mundo dinâmica, de forma a interagir e atuar na sociedade contemporânea. Para García (1998), a construção do conhecimento científico escolar deve estar vinculada às questões sociais, culturais, políticas e econômicas, tornando-se fundamental para tratar as situações-problemas, tais como as relações imbricadas entre a ação do homem na natureza. Nessa perspectiva, defende-se a necessidade de incorporar a complexidade para lidar com as questões de natureza aberta, como é o caso das questões socioambientais.

García $(2004$; 2017) aponta para uma reorganização do conhecimento, considerando os problemas ambientais como potenciais para isso. $\mathrm{O}$ autor defende a complexidade para uma mudança de visão de mundo, chama a atenção para o uso inadequado do discurso da descomplexificação com fins políticos/sociais. Para ele, diminuir a 
complexidade de um sistema social e educacional, por exemplo, consiste em romper com uma visão de mundo estático e simplicador, em prol de uma nova visão dinâmica e articulada com outras esferas do conhecimento. García (2017) argumenta que o desenvolvimento de uma EA na perspectiva da complexidade deve promover uma cultura que trata das questões voltadas ao meio ambiente com base na ética ambiental e nas habilidades em resolver e solucionar problemas.

Essa cultura alternativa deve ser construída com o objetivo de formar um indivíduo capaz de compreender e atuar no seu meio. Assim, a EA não tem a função de desenvolver determinados hábitos ambientalistas, mas proporcionar uma mudança de pensamento e conduta, que permite mostrar a inexistência de uma verdade absoluta sobre todas as coisas, mas uma verdade relativa. Nesse contexto, o desenvolvimento de um conhecimento aberto, dinâmico e integrado, possibilita a formação de um cidadão capaz de ser tornar consciente e responsável, criando seu próprio saber do mundo.

Vale ressaltar que o autor defende a ideia de descomplexificação como a necessidade de desenvolver um sistema com menos produção e consumo, do ponto de vista da EA isso implica em mediar de forma contextualizada a construção da autonomia do(a) aluno(a), possibilitando o desenvolvimento de um pensamento mais complexo do sistema. Nesse caso, o indivíduo torna-se capaz de tomar decisões em uma visão de mundo sistêmica, a causalidade entendida como interação e formação a cidadania para resolver problemas (GARCÍA; WATANABE, 2019).

Do ponto de vista da reflexividade, Beck (2010) discute os problemas acerca da sociedade de risco. Salienta que a reflexividade está atrelada às incertezas presentes nos discursos que apontam para os problemas socioambientais. Nessa perspectiva, a sociedade deve ser vista em meio a um processo de transição, nos quais entrelaçam fatores econômico, social, científico, entre outros. $\mathrm{O}$ autor procura explicitar os problemas socioambientais reconhecendo a impossibilidade de discutir tais questões de forma reducionista e linear; isso significa ter clareza de que nem todos os problemas socioambientais estão explícitos, assim como as relações que nele e dele se estabelecem. Além disso, pela própria natureza desses problemas, os posicionamentos dos indivíduos não devem ser estáticos e únicos, mas reflexivo, o que demanda um reposicionamento a cada novo argumento. Ao trabalhar a EA nessa perspectiva possibilidades de promover uma educação em que as relações sociais se estabelecem a ponto de promover uma participação efetiva do sujeito no processo de desenvolvimento social.

Diante do exposto, a formação de umindivíduo contemporâneo, quando ligado aos aspectos voltados a uma EA pautada na Criticidade, 
Complexidade e Reflexividade podem favorecer competências e habilidades para lidar e interagir com transformações e situações de problemas enfrentados no cotidiano, saindo de uma EA simplificadora, ambientalista e reducionista para uma EA fundamentada nas relações sociais, políticas, econômicas, culturais e científicas.

\section{HIPÓTESES DE TRANSIC̣ÃO: O PROCESSO DE CONSTRUC̣ÃO DO CONHECIMENTO DOS(AS) ESTUDANTES}

García $(1998,2004 ; 2017)$ defende que a construção do conhecimento escolar sofre influência do conhecimento científico, aquele desenvolvido nas academias por grupos de pesquisadores; e é enriquecido pelo conhecimento cotidiano, aquele estabelecido por uma comunidade para resolver problemas práticos do dia-a-dia. Nessa perspectiva, o conhecimento construído nas escolas não é um conhecimento universal, mas dinâmico e aberto, com sua própria natureza. Essa releitura pode levar a interpretação de que um cientista pode não ter habilidade para ensinar ciências, da mesma forma que um educador não tem formação para fazer pesquisa específica na área da Física, por exemplo.

Em suma, essa consideração - necessidade de construir um conhecimento científico escolar que considera as ideias primeiras dos indivíduos (conhecimento cotidiano) e o conhecimento organizado da Ciência (conhecimento científico) - indica que o processo de ensinoaprendizagem pode promover uma formação mais abrangente, pautada por argumentos mais complexos.

Ainda nessa perspectiva, e para compreender a construção das ideias dos(as) estudantes, Rodríguez-Marín; Fernández-Arroyo e García (2014) defendem que as hipóteses de transição são instrumentos que contribuem para identificar a construção dos argumentos, seus progressos e estabilizações durante o processo de aprendizagem. Essas hipóteses dão suporte para que o(a) docente tenha um panorama dos avanços e retrocessos de seus alunos(as), de acordo como o desenvolvimento do conhecimento científico escolar.

$\mathrm{Na}$ Figura 1, de modo simplificado, representam-se as formas de interação possíveis que podem levar às hipóteses de transição desejadas. Os dados iniciais (A1, B1, C1 e D1.) são considerados ideias primeiras dos(as) alunos(as), ou conhecimento cotidiano, e os seguintes (A2, A3, B2, B3 etc) são concretizadas ou reorganizadas de acordo com a aprendizagem alcançada. 
FIGURA 1. Construção do conhecimento científico escolar, a partir da evolução de um sistema de ideias (García,1998)

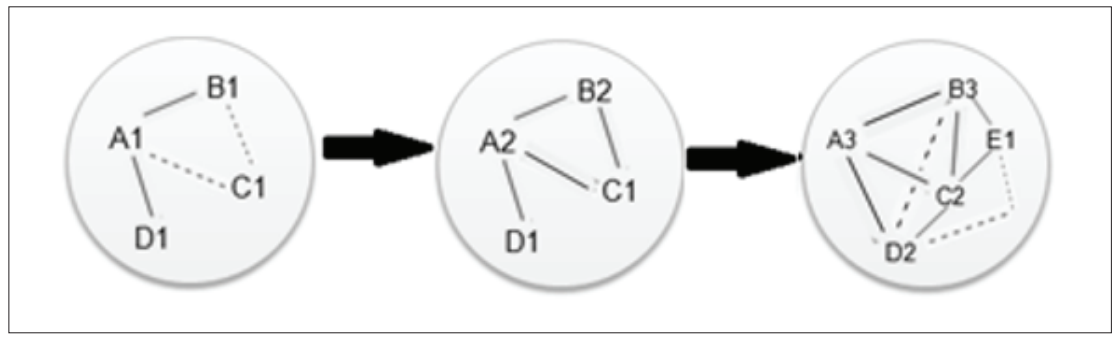

Fonte: García (1998. p. 151)

As interações representadas por linhas contínuas são consideradas fortes; e as representadas por linhas tracejadas referemse às ideias fracamente estabelecidas. Nota-se que a passagem de uma reestruturação fraca para outra forte ocorre a partir do envolvimento de outros elementos ou da reorganização do conhecimento cotidiano enriquecido, por exemplo, pelos conceitos científicos. Salienta-se que a reestruturação forte incorpora outras interações podendo levar a um pensamento mais complexo.

Do ponto de vista do processo de ensino-aprendizagem, a reflexão pautada em García (1998) contribui para que o(a) professor(a) possa acompanhar o processo de aprendizagem de forma contínua e não apenas em momentos específicos/pontuais. Ao construir uma proposta para as aulas sobre o AG, as hipóteses de transição podem contribuir na orientação das ações em sala de aula. Isso significa, por exemplo, identificar os caminhos percorridos por cada indivíduo, compreendendo seus argumentos diante do contexto inserido, suas construções e participações.

\section{ESTRATÉGIAS E DESENVOLVIMENTO DA PESQUISA}

A proposta de aulas sobre AG produzida com ajuda de professores e professoras das redes particular e pública do ensino básico e pesquisadores de distintas áreas assim como o contexto da escola participante foram determinantes para a construção de estratégias adotadas. Nesse sentido, a cada interação com os sujeitos da pesquisa novas abordagens foram sendo construídas e, é partir disso, que a seguir apresentam-se o contexto da pesquisa e as estratégias adotadas.

\section{A PROPOSTA DE AULAS COMPLEXIFICADA SOBRE AQUECIMENTO GLOBAL}

A proposta de aulas complexificada refere-se a um conjunto de aulas de Física para o EM sobre o tema AG. Ela foi desenvolvida 
pelo Grupo de Ensino de Ciências e suas Complexidades ${ }^{1}$ (GrECC) que teve como eixo principal dar oportunidade para docente realizar suas escolhas, considerando as distintas realidades escolares. Para promover essa autonomia, a proposta foi organizada em Momentos (1, 2, 3, 4 e 5). De modo geral, o Momento 1 se refere à problematização inicial, tem como objetivo iniciar um diálogo AG e estabelecer um compromisso com as turmas. Para tanto, faz-se um levantamento das possíveis causas e consequências do $A G$ que se voltam às ideias do tipo "efeito estufa", "derretimento das geleiras", "desmatamento das florestas", "emissão de $\mathrm{CO}_{2}$ ", "terremoto" etc.

O Momento 2, que se refere à medida da temperatura do entorno da escola, propõe uma atividade de coleta de temperatura usando um termômetro de máxima e mínima. O objetivo dessa atividade é abordar os erros e incertezas na leitura de dados. Em aula, a discussão consiste em estabelecer os procedimentos para a coleta de dados, a saber: registrar os dados durante um tempo mínimo de 10 dias; montar uma tabela com os dados; construir um gráfico de temperatura em função do tempo; e calcular a temperatura média.

O Momento 3, que se refere aos estudos dos conceitos de Física acerca do AG, pauta-se em diversas aulas, a saber: (i) revisita aos conceitos de Física; (ii) balanço dos fluxos de energia na Terra e equilíbrio dinâmico; (iii) efeito estufa e suas representações; e (iv) discussão dos dados coletados do Momento 2. Em (i) discutem-se os conceitos de calorimetria, temperatura e energia. Em (ii) retoma-se a discussão da última aula e inicia a abordagem acerca dos sistemas (aberto, fechado e isolado) para então tratar o conceito de equilíbrio dinâmico e balanço dos fluxos de energia do planeta Terra. Em (iii) as reflexões voltam-se ao efeito estufa, tempo de residência dos gases na atmosfera e proposição de uma atividade que visa identificar possíveis erros e limitações contidos nas representações do efeito estufa, presentes na mídia. Em (iv) analisam-se os dados coletados durante 24 dias sobre as medidas de máxima e mínima da temperatura no entorno da escola, além de construir e interpretar o gráfico de temperatura em função dos dias de observação.

$\mathrm{O}$ Momento 4, que se referem às polêmicas e discussões sobre o AG, explicitam-se os distintos pontos de vistas dos cientistas, políticos e representações sociais sobre o tema. Essa discussão foi desenvolvida com o intuito de promover um debate em sala de aula. Dessa forma, incentivam-se os(as) alunos(as) a se posicionarem considerando os argumentos de outras esferas do conhecimento tais como os dos cientistas céticos e ortodoxos, governo e sociedade. 
No Momento 5, que se refere à sistematização e síntese, discutese a questão "O que dizer sobre o AG?”. Propõe-se uma reflexão sobre as ações humanas que podem contribuir para a mudança de postura diante dos problemas socioambientais. O foco está na discussão acerca das intervenções humanas e as mudanças socioambientais.

\section{O CONTEXTO DE PESQUISA}

A pesquisa foi desenvolvida em uma escola pública localizada na zona sul da cidade de São Paulo, Brasil. Participaram quarenta estudantes, distribuídos em duas turmas do $3^{\circ}$ ano do EM, com idade entre 15 e 17 anos. A opção por trabalhar com essas turmas deve-se à estruturação do currículo escolar, visto que os(as) estudante já teriam estudado conceitos da Termodinâmica. $\mathrm{O}$ registro das produções dos(as) alunos(as) foi esquematizado em uma folha em branco com apenas a questão base "A Terra está esquentando? Como saber?". Essa questão foi revisitada e respondida em quatro etapas distintas ao longo dos Momentos das aulas. Optou-se por esse tipo de abordagem visto que, ao analisar o processo, foi possível identificar e compreender os usos dos elementos presentes nas ideias dos(as) estudantes, aspectos que levam a organização das hipóteses de transição. Nessa perspectiva, em cada momento de reescrita, o(a) aluno(a) tem a autonomia de modificar ou complementar suas reflexões de acordo com o conhecimento científico escolar construído até o momento.

A análise desse material se deu por meio da Análise Textual Discursiva (ATD) (MORAES e GALIAZZI, 2007), que considera a construção das categorias temáticas. Destacam-se que essas categorias servem de referência para a análise e, de certo modo, como sistematizadoras das intenções do(a) professor(a) que organiza suas aulas considerando a incorporação de mais elementos ao longo do tempo.

Tendo como base os argumentos trazidos pelos(as) alunos(as) estabeleceu-se um sistema de categorias a partir da identificação das hipóteses de transição (RODRÍGUEZ-MARÍN; FERNÁNDEZARROYO; GARCÍA, 2014). Para isso, realizou-se uma leitura das respostas dos(as) alunos(as) considerando as quatro etapas de coleta de dados, nas quais os(as) estudantes poderiam revisitar suas respostas, modificando ou aprofundando tópicos que considerassem necessários. Das categorias encontradas destacam-se: CC (Conhecimento Cotidiano); CEC1 (Conhecimento Científico Escolar Complexificado 1); CEC2 (Conhecimento Científico Escolar Complexificado 2); e CEC3 (Conhecimento Científico Escolar Complexificado 3).

Para cada uma das categorias supracitadas foram obtidos dados (dispostos em 4 etapas de coleta de dados). Os espaços da coleta de 
dados e as categorias se relacionam da seguinte forma: CC (1 $1^{\text {a }}$ etapa da coleta): ocorreu antes do desenvolvimento do Momento 1; CEC1 ( $2^{\text {a }}$ etapa da coleta): ocorreu entre o final do Momento 2 e início do Momento 3; CEC2 (3 $3^{a}$ etapa da coleta): ocorreu ao término do Momento 3 , especificamente, ao discutir sobre os conceitos de equilíbrio dinâmico, tempo de residência, efeito estufa e intervenção humana na Terra; CEC3 ( $4^{a}$ etapa da coleta): ocorreu no final da proposta, após a discussão dos Momentos 4 e 5.Salienta-se que a partir dessas categorias foi possível identificar as transições das ideias dos(as) alunos(as) que, para esse artigo, optou-se por tratar de cinco percursos distintos. A escolha desses estudantes se deu apenas por considera-los exemplos de cada uma das formas de construções encontradas na pesquisa.

\section{RESULTADOS: PERCURSOS DAS IDEIAS DOS(AS) ESTUDANTES SOBRE O AG}

Para identificar aspectos que levam ao conhecimento científico escolar desenvolvido pelos(as) alunos(as) partir das hipóteses de transição (RODRÍGUEZ-MARÍN; FERNÁNDEZ-ARROYO; GARCÍA, 2014), ou seja, a evolução de ideias durante a proposta sobre o AG, optou-se por analisar alguns percursos dos(as) alunos(as) a partir das categorias já apresentadas.

Em CC estão presentes as ideias iniciais dos(as) estudantes acerca do AG, sem influência do conhecimento científico escolar sistematizado nas aulas de Física. No geral, as respostas estão fundamentadas nos argumentos voltados aos discursos presentes na mídia e nos meios de comunicação, à sensação térmica e/ou observação dos fenômenos mais gerais para explicar a natureza. As respostas em CC apontam para a possibilidade de um aumento da temperatura da Terra e subdividem-se em: Hipótese de transição A (discurso dos vínculos de comunicação), Hipótese de transição B (sensações térmicas/sentidos) e Hipótese de transição C (fenômenos da natureza observados de forma direta).

Em CEC1 encontram-se ideias pautados nos conceitos escolares de Física que, de forma geral, foram tratados nas primeiras aulas sobre o AG. Nessa etapa, na qual se inicia uma reflexão um pouco mais sistematizada do ponto de vista do conhecimento científico escolar, identifica-se a Hipótese de transição $\mathbf{D}$, a qual relaciona os argumentos que questionam os meios de comunicação e mídia; e a Hipótese de transição $\mathbf{E}$, que traz argumentos baseados nos conceitos escolares da Física.

Em CEC2 encontram-se as respostas que se baseiam nos conceitos escolares da Física vinculados a algum posicionamento do(a) aluno(a). Nota-se que o conhecimento cotidiano se torna mais 
complexificado nas etapas que seguem, pois o(a) estudante tem a oportunidade de se aproximar de outros aspectos do conhecimento cientifico, seja esse compartilhado por uma visão cética ou visão ortodoxa. As respostas presentes nessa categoria dividem-se em: Hipótese de transição $\mathbf{F}$, que traz argumentos que englobam uma visão cética, partindo da ideia de que o $A G$ é causado pela dinâmica da própria natureza; e Hipótese de transição $\mathbf{G}$ que traz uma visão ortodoxa, na qual fenômeno do aquecimento é causado quase que exclusivamente pela ação humana.

Em CEC3 encontram-se respostas que se baseiam nos conceitos escolares da Física articulados com as outras áreas do conhecimento. Ou seja, incorporam elementos no conhecimento cientifico escolar procurando articulá-los com outras esferas do conhecimento (científico, social, econômica, cultural etc.). Na Hipótese de transição $\mathbf{H}$ estão os argumentos pautados nas incertezas das medidas articulados com ações de conservação da natureza e a questão da sustentabilidade como possíveis mudanças de postura, mostrando a preocupação com as transformações de hábito (consumo exagerado).

Em suma, a partir das categorias organizam-se as hipóteses de transição que, do ponto de vista da construção das ideias, implicam na incorporação de novos elementos nos discursos dos(as) alunos(as), refletindo seus percursos ao longo do processo ensino-aprendizagem $O$ Quadro 1 apresenta as categorias e as suas respectivas hipóteses de transição.

QUADRO 1. Categorias e hipóteses de transição

\begin{tabular}{|c|l|}
\hline \multirow{2}{*}{ Categorias } & \multicolumn{1}{c|}{ Hipóteses de Transição } \\
\hline \multirow{2}{*}{ CC } & Hipótese de transição A - Certezas sobre mídia \\
\cline { 2 - 3 } & Hipótese de transição B - Sensações térmicas/Sentidos \\
\cline { 2 - 3 } & Hipótese de transição C - Fenômenos da natureza observados de forma direta \\
\hline \multirow{2}{*}{ CEC1 } & Hipótese de transição D - Questionamentos sobre a mídia \\
\cline { 2 - 3 } & Hipótese de transição E - Conceitos escolares da Física \\
\hline \multirow{2}{*}{ CEC2 } & Hipótese de transição F - Conceitos escolares da Física e visão cética \\
\cline { 2 - 3 } & Hipótese de transição G - Conceitos escolares da Física e visão ortodoxa \\
\hline \multirow{2}{*}{ CEC3 } & Hipótese de transição H - Conceitos escolares da Física, sustentabilidade e consumo \\
\hline
\end{tabular}


A partir dessa sistematização, a discussão que segue analisa o percurso de cinco estudantes, a saber: A18 que alcançou a CEC1, em fase de transição para CEC2; A01 e A09 que alcançaram a CEC2; e A12 e A30 que alcançaram a CEC3.

\section{PERCURSO DAS IDEIAS DE A18}

No primeiro momento da coleta de dados, a resposta de A18 baseia-se nos argumentos presentes na Hipótese de transição C. A discussão trata dos fenômenos da natureza observados de forma direta, sem efetivamente discorrer sobre o assunto. É quase uma repetição de termos com pouco significado. Assim, por exemplo, o(a) aluno(a) apenas cita o derretimento das geleiras e as queimadas como elementos causadores do aquecimento da Terra. O diagrama a seguir e o trecho da fala indicam a condição inicial de A18.

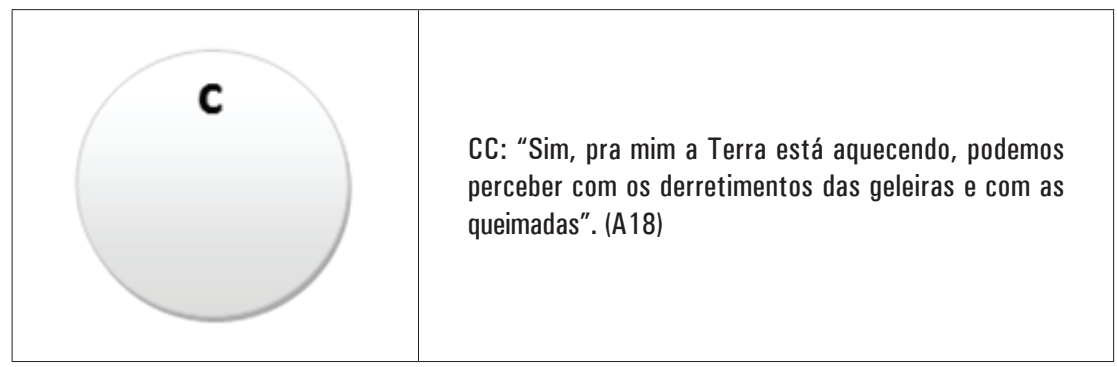

No segundo momento de coleta de dados, A18 encontra-se na Hipótese de transição E. Isso ocorre porque ele(a) menciona os conceitos escolares da Física, tais como o equilíbrio dinâmico, para justificar a questão problematizadora. A resposta também aponta para um discurso embasado em uma visão mais ortodoxa, que nos leva à Hipótese de transição G. Nesse caso, ele(a) menciona a ação humana influenciando a natureza por meio das construções das indústrias, utilização dos carros e desmatamentos. Para representar essa relação foram utilizadas linhas pontilhadas, pois tal argumento aponta para uma ligação fraca frente ao uso de justificativas pautadas na perspectiva dos conceitos escolares da Física (Hipótese de transição E). Essa ligação mostra que o(a) aluno(a) parece estar em uma fase de transição de um pensamento mais simples para outro mais complexo. O diagrama a seguir e o trecho da fala indicam a condição atual de A18. 


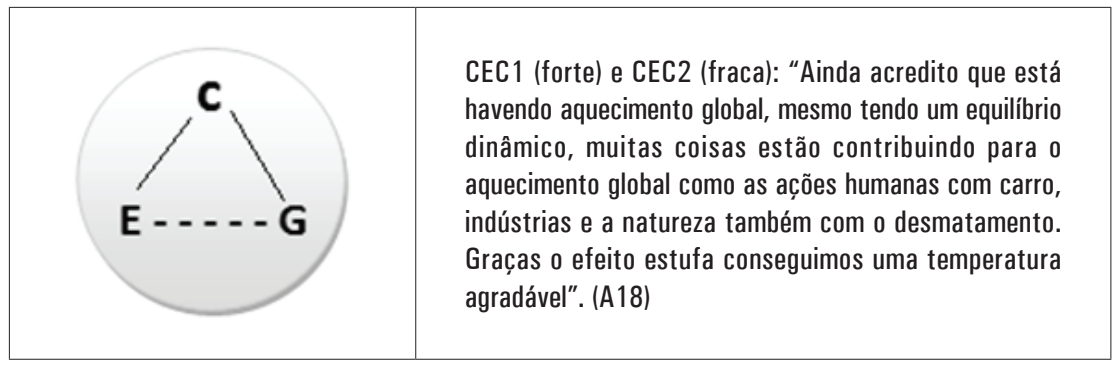

No terceiro momento da coleta de dados, A18 permanece na mesma categoria (CEC1), pois não incorpora outros elementos em seus argumentos. No entanto, cabe salientar que o(a) aluno(a) mostra algum incomodo ao ter contato com os gráficos e modelos acerca do AG. Parece que esse é um momento crucial para a mudança de posicionamento ou para a sua manutenção. Novamente, A18 parece permanecer em uma fase de transição. O diagrama a seguir e o trecho da fala indicam a condição atual de A18.

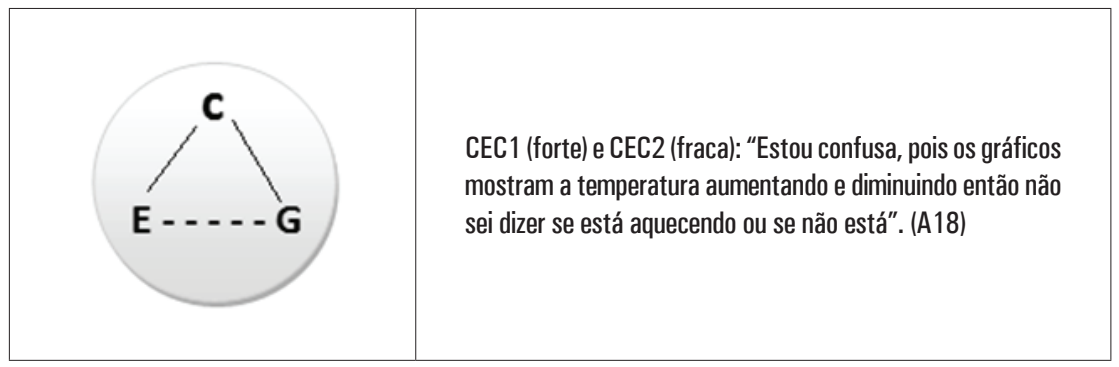

No quarto momento de coleta de dados, A18 se aproxima do discurso presente na Hipótese de transição F. Essa hipótese trata de uma visão mais cética acerca do AG. A análise mostra que o(a) aluno(a) se distancia da ideia de que o homem é o maior responsável pelo AG e passa a defender a relação menos direta e catastrófica do homem em relação a natureza. Em sua resposta é possível identificar elementos que levam às questões da incerteza. Vale destacar que nessa hipótese os conteúdos conceituais estão presentes; mas no caso de A18 essa relação é fraca, o que justifica a ligação tracejada no diagrama. Esse aluno(a) ainda parece estar em uma fase de transição. Como o sistema de ideias é dinâmico e flexível, acredita-se que o tempo de construção de seus argumentos ocorra após as 20 aulas dadas. O diagrama a seguir e o trecho da fala indicam a condição atual de A18. 


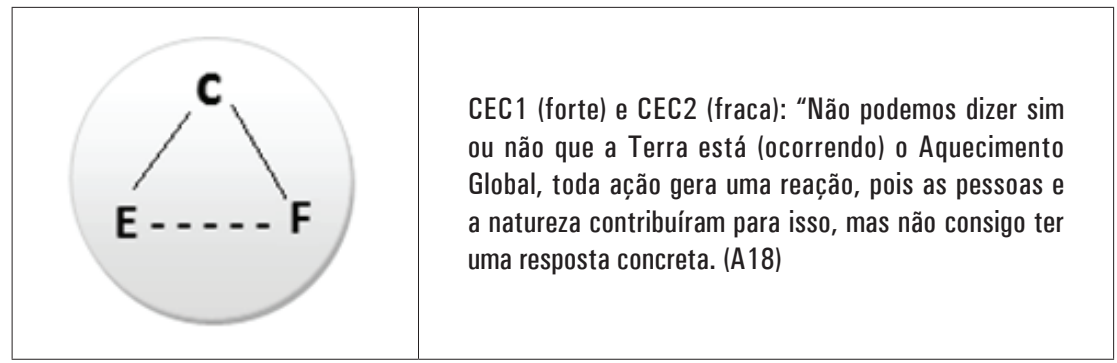

PERCURSO DAS IDEIAS DE A01

O A01 para no primeiro momento da coleta de dados está na Hipótese de transição B. Nela destaca-se o discurso pautado na sensação térmica, ou seja, nos sentidos apenas. A01 também salienta que a Terra não está aquecendo e tais informações podem ser observadas em gráficos e pesquisas. Esse posicionamento nos leva identificar argumentos presentes na Hipótese de transição A, ainda que apareçam de forma indireta e subentendida. Essa é uma ligação fraca, representada pela linha tracejada. O diagrama a seguir e o trecho da fala indicam a condição inicial de A01.

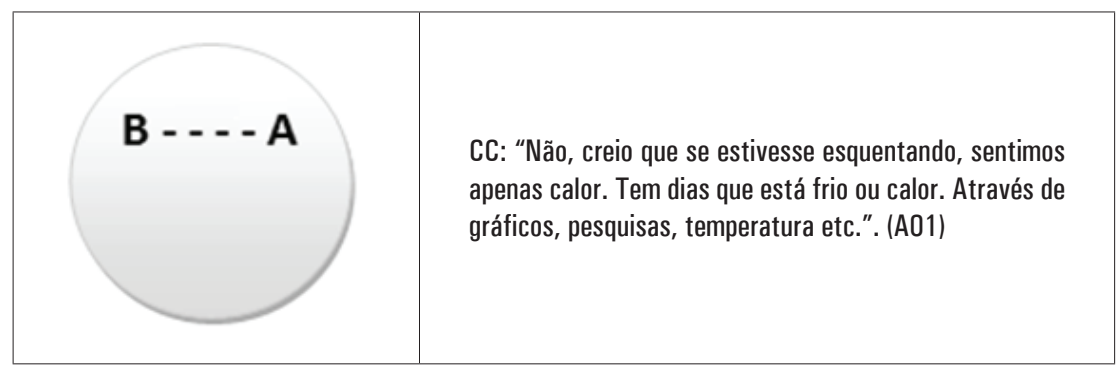

No segundo momento da coleta de dados, A01 incorpora em sua escrita aspectos mais próximos de um conhecimento científico escolar, tais como tempo de residência e fluxo de "calor". Nesse sentido, A01 passa a ter uma ligação forte que o leva à Hipótese de transição E. O diagrama a seguir e o trecho da fala indicam a condição atual de A01. 


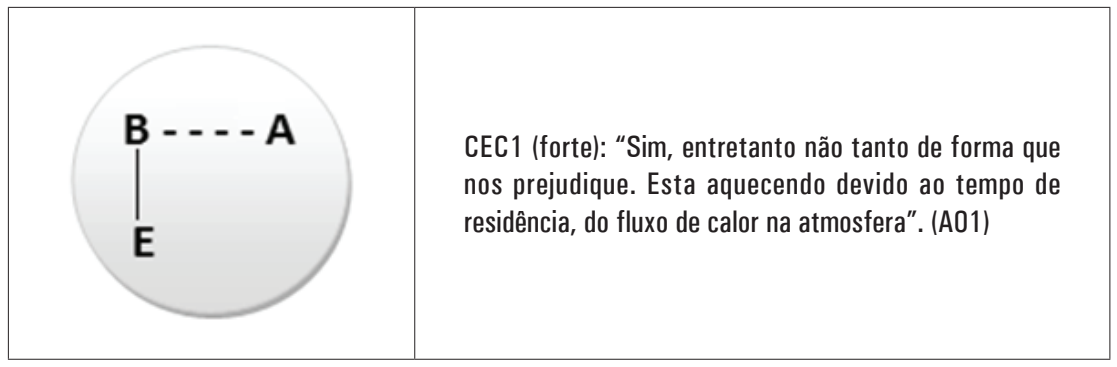

No terceiro momento de coleta de dados, A01 sistematiza suas ideias utilizando elementos presentes na Hipótese de transição F. Isso se deve ao explicitar ideias pautadas em uma visão cética frente à problemática socioambiental. Nota-se também que A01 traz elementos que o conecta de forma forte com a Hipótese de transição E. O que justifica tal ligação é a consideração de que o planeta é dinâmico, por exemplo. O diagrama a seguir e o trecho da fala indicam a condição atual de A01.

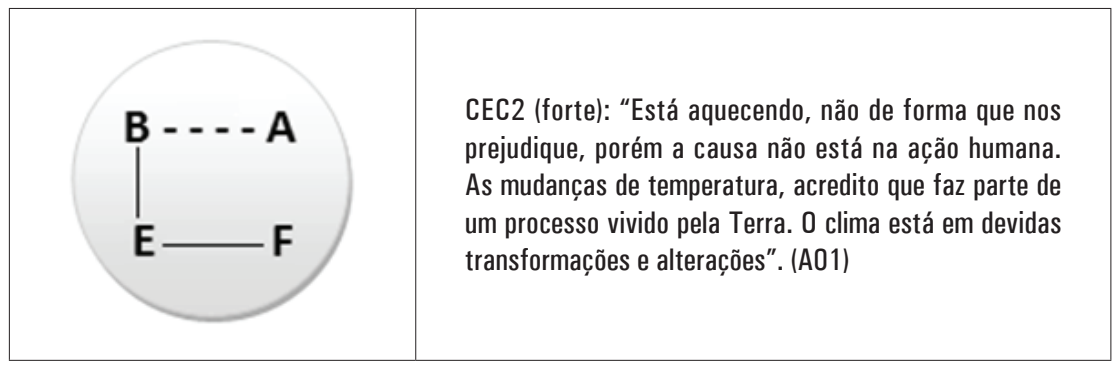

No quarto momento de coleta de dados, A01 repete a construção anterior, ou seja, não incorpora elementos de outros níveis do conhecimento (CEC3). Essa postura mostra que sua "evolução" nos sistemas de ideias não mais ocorre, pelo menos do ponto de vista do conhecimento científico escolar complexificado. O diagrama a seguir e o trecho da fala indicam a condição atual de A01.

\begin{tabular}{|l|l|}
\hline & $\begin{array}{l}\text { CEC2 (forte): "Está esquentando, não por cauda do } \\
\text { homem e sim por conta de causas naturais, processo } \\
\text { vivido pela Terra, os problemas ambientais do homem de } \\
\text { nada interferem no aquecimento. Mudanças climáticas } \\
\text { sempre ocorreram desde a origem da Terra com ou sem a } \\
\text { interferência humana. Acredito que haja manipulação dos } \\
\text { dados de temperatura terrestre". (A01) }\end{array}$ \\
\hline
\end{tabular}




\section{PERCURSO DAS IDEIAS DE A09}

As ideias de A09 no primeiro momento de coleta de dados estão inseridas na Hipótese de transição C. Essa hipótese utiliza os fenômenos da natureza como eixo central para os argumentos produzidos. A09 cita, por exemplo, a poluição da atmosfera devido ao uso de carros ou desmatamentos das florestas. O diagrama a seguir e o trecho da fala indicam a condição atual de A09.

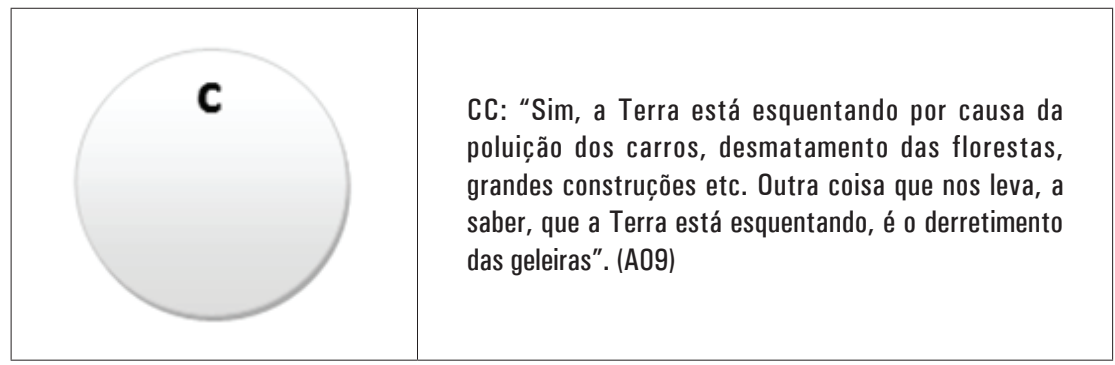

No segundo momento, A09 aproxima-se da Hipótese de transição E ao trazer para seu discurso o fenômeno de irradiações solar e absorção pela camada atmosférica. O diagrama a seguir e o trecho da fala indicam a condição atual de A09.

\begin{tabular}{|l|l|}
\hline & $\begin{array}{l}\text { CEC1 (forte): “Sim, a Terra está esquentando, a } \\
\text { atmosfera da Terra está armazenando o calor que vem das } \\
\text { radiações e gases servindo como cobertor para a Terra e } \\
\text { proporcionando, a nós seres humanos, uma temperatura } \\
\text { harmônica e confortável, Há muito tempo a temperatura } \\
\text { da Terra era }-21^{\circ} \text { e hoje são } 15,5^{\circ} \text { é possível notar que } \\
\text { houve um aumento na temperatura, por tanto podemos } \\
\text { concluir que a Terra está aquecendo" (A09) }\end{array}$ \\
\hline
\end{tabular}

No terceiro momento, A09 consolida sua resposta ao trazer argumentos presentes na esfera do conhecimento científico escolar. A09 aproxima-se da Hipótese de transição $G$ por meio de uma ligação fraca, pois houve incorporação de uma visão ortodoxa ligada à frase "poluentes que emitimos na Terra". O diagrama a seguir e o trecho da fala indicam a condição atual de A09. 


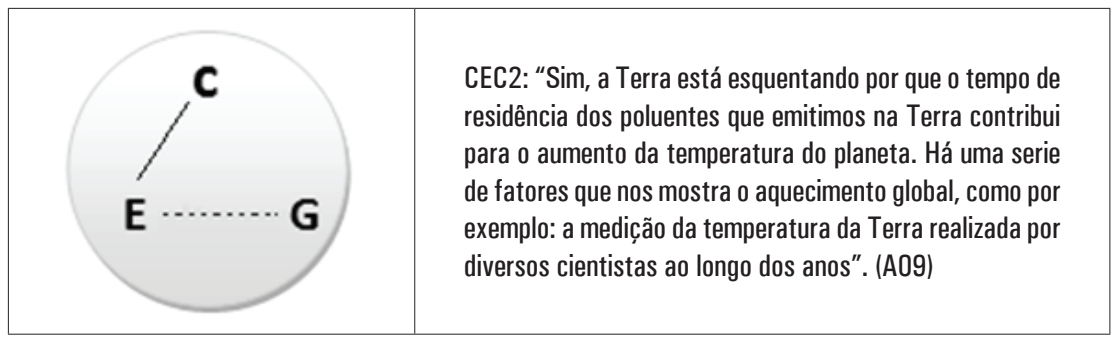

No quarto momento da coleta de dados, A09 parece permanecer em CEC2. Isso se deve porque o(a) aluno(a) não estruturou ou complementou suas ideias de forma clara. De certa forma, ele(a) se mostra satisfeito(a) com a resposta que estrutura sua rede de conhecimentos. O diagrama a seguir e o trecho da fala indicam a condição atual de A09.

\begin{tabular}{|l|l|}
\hline CEC2: “(...) a Terra está aquecendo sim, e a maneira \\
mais fácil de constatar esse fato é observar o aumento \\
da temperatura da Terra ao longo dos anos, porém, as \\
medições não são tão precisas como parece ser, por que \\
precisamos medir a temperatura da Terra inteira. E com \\
essas medições são feitas através de termômetros e são \\
controladas por seres humanos, que podem falhar nos \\
horários e deixar de anotar as medidas (...)”. (A09)
\end{tabular}

\section{PERCURSO DAS IDEIAS DE A12}

No primeiro momento da coleta de dados, A12 parece descrever com certa clareza os fenômenos observados na natureza, o que o coloca na Hipótese de transição C. Isso ocorre quando A12 se refere às estações do ano (primavera, verão, outono e inverno). $\mathrm{O}$ diagrama a seguir e o trecho da fala indicam a condição atual de A12.

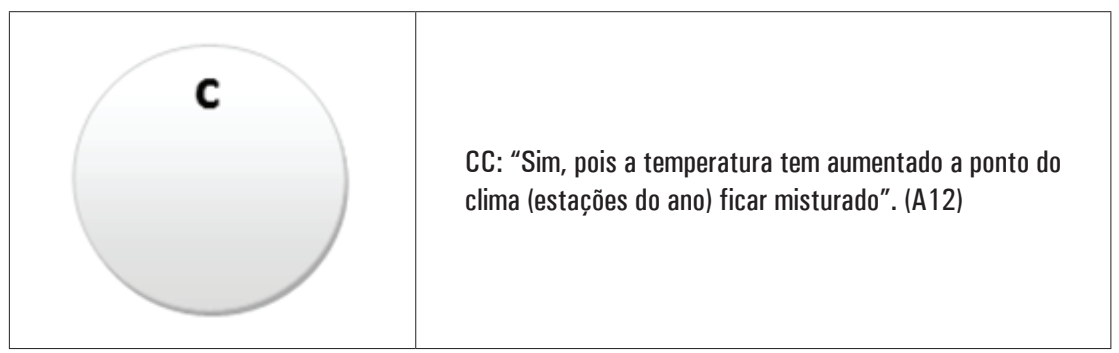

No segundo momento de coleta de dados, A12 pauta-se em argumentos presentes em CEC1, tendo como base a Hipótese de transição E. Isso ocorre visto que aparecem em sua resposta conceitos 
escolares da Física, especificamente, voltados à dinâmica da atmosfera. A12 também traz argumentos pautados na Hipótese de transição D ao apontar para aspectos da mídia. Esse(a) aluno(a) parece estar fortemente ligado a esses dois aspectos - questionamentos da mídia e conceitos de Física, buscando argumentos para justificar os problemas apontados anteriormente (hipótese de transição C). O diagrama a seguir e o trecho da fala indicam a condição atual de A12.

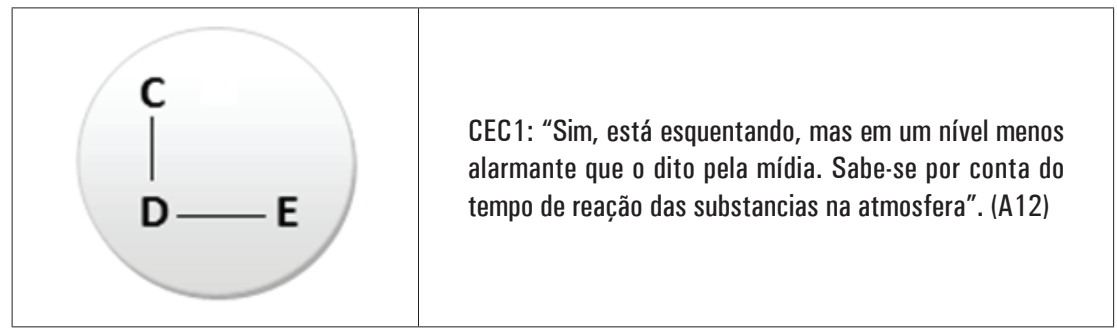

No terceiro momento da coleta de dados, A12 permanece com as mesmas ideias da etapa anterior. Dessa forma, não houve construção ou incorporação explícita de outros elementos que justificam suas respostas. O diagrama a seguir e o trecho da fala indicam a condição de permanência de A09.

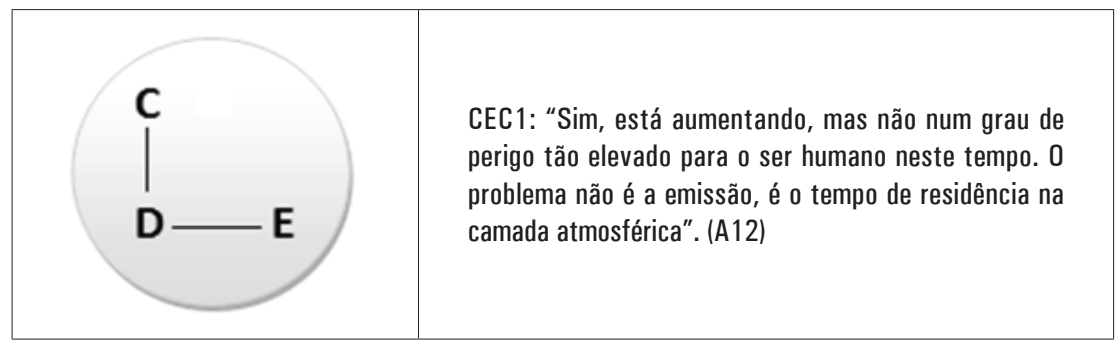

No quarto momento da coleta de dados, A12 demonstra preocupação com o futuro da sociedade, trazendo argumentos tais como: consumo exagerado e responsabilidades diante do AG. Nota-se que a Hipótese de transição H está atrelada a Hipótese de transição F, pois o(a) aluno(a) descreve o problema do AG como causa e efeito do homem e da natureza. Essa passagem é interessante, pois demonstra que A12 faz relações com argumentos de CEC2 muito tempo depois de se tratar do assunto em sala de aula. Ele(a) não necessariamente articulou sua resposta logo após ter discutido o assunto em sala de aula, mostrando o caráter dinâmico e pouco linear desse processo. $\mathrm{O}$ diagrama a seguir e o trecho da fala indicam a condição atual de A12. 


\begin{tabular}{|l|l|}
\hline CEC3: “A Terra está esquentando, mas a causa não é \\
imprudência humana, é natural. 0 CO2 que é tão falado, \\
não possui poder de esquentar a atmosfera, mesmo se \\
esquentasse (...). 0 grande problema não é a emissão e \\
nem a temperatura, até por que o aquecimento global \\
favorece a agricultura já que plantas respiram CO2, 0 \\
problema é a habilidade humana de degradar o meio em \\
que vive, esta deve ser a preocupação, os gases emitidos \\
são o de menos, o problema é o desmatamento para a \\
criação de um monte de lixo tóxico, lixo este que mantém \\
a economia rodando e o consumismo desenfreado \\
existente, acabando de fato com o planeta". (A12)
\end{tabular}

\section{PERCURSO DAS IDEIAS DE A30}

No primeiro momento de coleta de dados, as ideias de A30 estão na Hipótese de transição A e C. Isso ocorre porque ele(a) apoia-se nos meios de comunicação para fundamentar sua resposta, justificando sua presença na Hipótese de transição A. E, ao mesmo tempo, traz elementos da Hipótese de transição $\mathrm{C}$ ao citar os fenômenos que ocorrem na natureza como, por exemplo, derretimento das geleiras e desmatamento das árvores. O diagrama a seguir e o trecho da fala indicam a condição atual de A30.

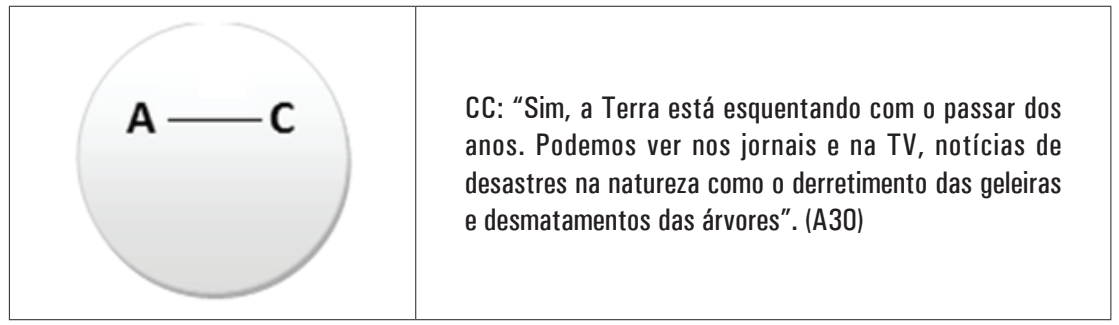

No segundo momento de coleta de dados, A30 pauta sua resposta na Hipótese de transição $\mathrm{E}$ ao utilizar os conceitos escolares da Física, tais como: equilíbrio dinâmico e tempo de residência dos gases na atmosfera. O diagrama a seguir e o trecho da fala indicam a condição atual de A30.

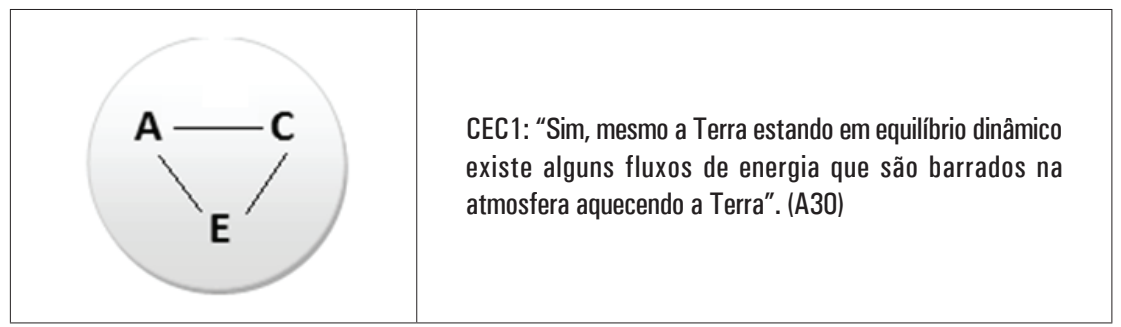


No terceiro momento, A30 permanece pautado nos conceitos escolares da Física para justificar seu posicionamento, tais como: tempo de residência dos gases na atmosfera (aspectos físicos) e desenvolvimento da espécie humana no planeta (aspectos biológicos). Nesse sentido, ele(a) se encontra na Hipótese de transição E. Vale ressaltar que diante da afirmação "excesso de gases aqueça a Terra", considerou-se que A30 está na Hipótese de transição $G$ de forma fraca. O diagrama a seguir e o trecho da fala indicam a condição atual de A30.

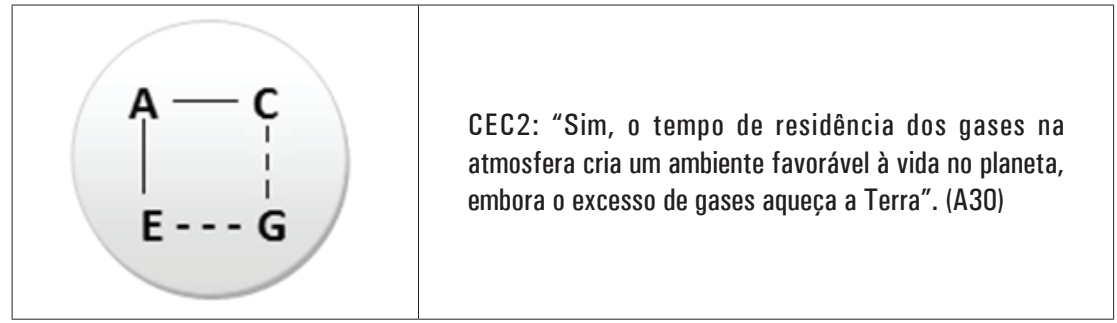

A30, no quarto momento de coleta de dados, apresenta argumentos que o leva à Hipótese de transição H. Exemplo disso ocorre ao mencionar os problemas causados pelo consumo exagerado. Nota-se que esse posicionamento se fortalece ao mencionar, no primeiro momento, os problemas do desmatamento. Com isso, é possível identificar uma ligação forte entre a Hipótese de transição H e C. Vale ressaltar que A30 também incorpora em sua resposta aspectos da esfera educacional, salientando que uma possível solução para o problema do AG reside na conscientização. O diagrama a seguir e o trecho da fala indicam a condição atual de A30.

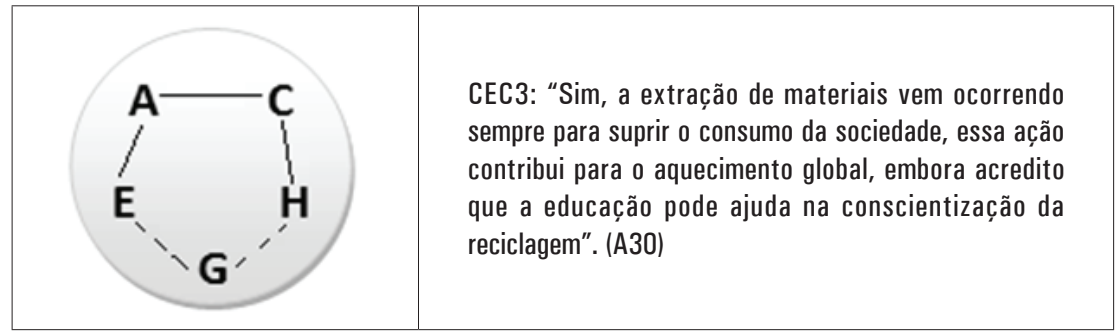

No que concerne os resultados mais gerais, a Figura 2 mostra comparativamente o processo de construção do conhecimento dos(as) estudantes. Nota-se que ao longo das reflexões e da análise das hipóteses de transição ficou evidente que o conhecimento científico escolar não se estabelece de forma contínua e sequencial, seguindo uma evolução caótica e dinâmica, ou seja, suas ideias são organizadas ou reconstruídas constantemente ao longo da proposta. Assim, não se 
trata de um processo linear com a incorporação de elementos, mas as ideias vão se organizando e reorganizando de forma dinâmica e ativa.

FIGURA 2. Os diagramas que representação as hipóteses de transição de A18, A01, A09, A12 e A30 na construção do conhecimento científico escolar.

Alunos(as) Construção do conhecimento científico escolar

O diagrama do A18 representa uma estruturação forte no CEC1, e parece estar próximo de construir relações com os argumentos presentes em CEC2 estabelecido nesse momento por uma ligação fraca. Seu posicionamento acerca do AG mostra-se em fase de transição o que, no momento da análise, não estabelece relações que podem levam a uma EA na perspectiva da criticidade, complexidade e reflexividade. Já os diagramas A01 e A09 mostram a construção das ideias, ainda que com suas peculiaridades, alcançado CEC2. Esses(as) alunos(as) mostram em suas respostas um grau maior de complexidade quando comparado com o A18. Vale recordar que a organização de 
CEC2 as hipóteses apontam para maior integração ou sistematização das ideias dos(as) alunos(as) por meio de uma estrutura forte.

Os diagramas A12 e A30 apresentam respostas com mais elementos da complexidade quando comparado com os(as) alunos(as) analisados(as) anteriormente. Assim, pode-se afirmar que os(as) alunos(as) citados(as) alcançaram o nível de aprendizagem planejado inicialmente pela professora. Cabe destacar que tanto A12 quanto A30 identificaram a necessidade de aproximar o conhecimento cotidiano, aquele vivenciado no dia-a-dia, com as questões de natureza científica, social, política, econômica e cultural. Isso pode ser observado quando os(as) alunos(as) apontam nos seus argumentos a Hipótese de progressão $\mathrm{H}$, que está pautada nas questões das incertezas e nas possíveis mudanças de postura e hábitos, como exemplos temos as respostas de A12 ("o problema é o desmatamento para criação de um monte de lixo tóxico, lixo este que mantém a economia rodando e o consumo desenfreado") e A30 ("a extração de materiais vem ocorrendo sempre para suprir o consumo da sociedade").

\section{CONSIDERACÕ̃ES FINAIS}

Essa pesquisa investigou os percursos que os(as) alunos(as) constroem quando submetidos a uma proposta de aulas complexificada. Para tanto, considerou-se as hipóteses de transição que foram tomadas a partir das ideias dos(as) estudantes acerca das questões voltadas para o AG. A partir disso, procurou-se compreender aspectos que levariam a uma EA mais crítica, complexa e reflexiva.

Ao analisar as hipóteses de transição foi possível identificar elementos nas ideias dos(as) aluno(as) que ajudam o(a) docente compreender as relações estabelecidas na construção do conhecimento científico escolar. Nesse sentido, as hipóteses de transição podem ser consideradas um plano metodológico (RODRÍGUEZ-MARÍN; FERNÁNDEZ-ARROYO; GARCÍA, 2014), visto que possibilita orientar o(a) docente no desenvolvimento dos conteúdos trabalhados em sala de aula; e identificar os elementos manifestados pelos(as) alunos(as) durante a construção de suas ideias.

No segundo caso, identificar os elementos manifestados pelos(as) alunos(as) durante a construção de suas ideias, torna-se fundamental compreender como esses alunos e alunas 'caminham' nesse processo. Para isso, a discussão que seguiu procurou acompanhar a suas trajetória, tentando identificar quais escolhas foram realizadas ao saírem de uma abordagem caracterizada pelos baixos níveis 
de complexidade, com os discursos baseados em seu cotidiano (Hipótese de transição A), e alcançarem níveis mais complexos, nos quais incorporam aspectos de interação e reorganização do conhecimento científico escolar (Hipótese de transição H). A partir dos resultados, nota-se que não foram observados argumentos mais complexos e relacionados com outras esferas de conhecimento logo no inicio da atividade. Ao alcançaram níveis mais complexos, os(as) alunos(as) passam a incorporar questões da ciência e aspectos sociais. Vale destacar que nesse processo alguns(mas) estudantes não se mantém no nível mais alto de complexidade, mas transitam ou se estabilizam em outras níveis mostrando, com isso, a natureza flexível da construção do conhecimento escolar.

Assim, essas construções apontam para uma não linearidade, de forma que as representações apenas ilustram um momento no qual o(a) aluno(a) se apresenta no instante específico da proposta de aulas. Para nós fica claro que esse percurso é dinâmico e complexo, o que mostra a fase transitória do pensamento simples para outro mais complexo.

Do ponto de vista da EA crítica, complexa e reflexiva, notase que a proposta de aulas complexificada dá margem para que uma construção ideias menos reducionista e linear frente aos problemas ambientais. A busca por essa formação requer dar espaços para que os alunos e as alunas tenham a oportunidade de reconstruírem suas ideias (e posicionamentos) ao longo do processo. E para isso devem ter a liberdade de utilizarem conhecimentos de distintas natureza, com especial destaque ao escolar científico. Tal como salientam Watanabe-Caramello e Kawamura (2014) isso significa ter clareza de que nem todos os problemas ambientais estarão explícitos, assim como as relações que nele se estabeleça.

Por fim, há de considerar que a linearidade tão desejada pelas escolas parece ser apenas um guia para o(a) professor(a) ao delimitar seus objetivos, já que os caminhos percorridos pelos(as) estudantes se aproximem de uma teia muito mais complexa, sendo as hipóteses de transição como os nós dessa teia. Nos parece importante então buscar uma EA pautada na criticidade, complexidade e reflexividade que privilegie e considere um sistema de ideias dinâmico e caótico, mas com limitações e os tempos específicos de aprendizagens. 


\section{AGRADECIMENTOS}

O presente trabalho foi realizado com apoio da Universidade Federal do ABC (UFABC) que concedeu a Bolsa de Estudos do Programa de Pós-Graduação em Ensino e História das Ciências e da Matemática.

Ao Grupo de Ensino de Ciências e suas Complexidades (GrECC) que auxiliou na construção das estruturas temática e conceitual sobre o tema ambiental no contexto do ensino de Física Contemporânea, com apoio do MCTI /CNPq / MEC/CAPES N 18/2012.

A Fundação de Amparo à Pesquisa do Estado de São Paulo (FAPESP) pelo financiamento a pesquisa referente ao processo n²018/19136-3.

\section{REFERÊNCIAS}

BRASIL. Ministério da Educação. Secretaria de Educação Média. PCNs+ Ensino Médio: Orientações educacionais complementares aos Parâmetros Curriculares Nacionais. Ciências da Natureza, Matemática e suas Tecnologias. Brasília: MEC, 2002.

BRASIL. Ministério da Educação. Secretaria de Educação Fundamental. Orientações curriculares para o Ensino Médio. Brasília: MEC, 2006.

BRASIL. Diretrizes Curriculares Nacionais para o Ensino Médio. Brasília: MEC, 1998.

BECK, U. Sociedade de Risco. São Paulo: Editora 34, 2010.

FREIRE, P. Pedagogia do oprimido. Rio de Janeiro: Paz e Terra, 2005.

GARCÍA, J. E. Educacíon ambiental, constructivismo y complejidad. Série Fundamental, n. 21. Espanha: Díada Editora S. L., 2004.

GARCÍA, J. E. Hacia una teoría alternativa sobre los contenidos escolares. Espanha: Díada Editora S. L., 1998.

GARCÍA, J. E. Menos puede ser más (complejidad). Una reflexión sobre la interacción entre decrecimiento y complejidad. Universidad de Sevilla. Enseñanza de Las Ciencias, 2017.

GARCÍA, E. D; WATANABE. G. Menos pode ser mais: do decrescimento e descomplexificação à complexidade. Revista da Faculdade de Educação -UnB, p. 280-303, v.25, 2019.GUIMARÃES, M. Caminhos da educação ambiental: da forma a ação. Campinas, SP. $3^{\circ}$ edicão, 2008.

LOUREIRO, C, F, B. Caminhos da educação ambiental: da forma a ação. Campinas, SP. $3^{\circ}$ edicão, 2008

MARTÍN, R. P; RIVERO A.G; SOLÍS E. R. La progresión en el aprendizaje de la enseñanza de las ciencias de futuros maestros. X Congreso Internacional sobre Investigación en Didáctica de las Ciencias (2017), p 129-135. 2017. 
MORAES, R.; GALIAZZI, M. C. Análise Textual Discursiva. Ijuí, Editora Unijuí, 2007.

MORIN, E. Introdução ao pensamento complexo. $3^{\mathrm{a}}$ ed. Porto Alegre: Sulina, 2007.

RODRIGUEZ-MARÍN, F; FERNÁNDEZ-ARROYO, J; GARCÍA, J. Las hipótesis de transición como herramienta didáctica para la educación ambiental. Enseñanza de Las Ciencias, p. 300-318. 2014.

WATANABE-CARAMELLO; KAWAMURA, M. R. Uma educação na perspectiva ambiental crítica, complexa e reflexiva. Revista Brasileira de Pesquisa em Educação em Ciências. v. 14, n. 2, 2014.

\section{NOTAS}

${ }^{1}$ Grupo de Ensino de Ciências e suas Complexidades (GrECC, 2014) http://grecc.com.br/. O GrECC propõe a construção das estruturas temática e conceitual sobre o tema ambiental no contexto do ensino de Física Contemporânea.

Submetido: 01/06/2017

Aprovado: 06/04/2018

Contato:

Rua Rosa de Souza, n¹4

Bairro: Parque Novo Lar

São Paulo |SP|Brasil

CEP 03.928-250 